\title{
SSynthesis
}

International Scientific Conference of IT and Business-Related Research

\section{ANALIZA POSLOVNIH PRAKSI I PERSPEKTIVE RAZVOJA ONLAJN MARKETINŠKIH ISTRAŽIVANJA U SRBIJI}

\section{THE ANALYSIS OF BUSINESS PRACTICES AND DEVELOPMENT PERSPECTIVES OF ONLINE MARKET RESEARCH IN SERBIA}

\author{
Nikolina Ljepava ${ }^{1}$, Radmila Janičić ${ }^{2}$ \\ ${ }^{1}$ Fakultet za medije i komunikacije, Karađorđeva 65, Beograd \\ ${ }^{2}$ Fakultet Organizacionih Nauka, Jove Ilića 154, Beograd
}

\begin{abstract}
Apstrakt:
Istraživanja na Internetu postaju sve zastupljeniji vid tržišnih i društvenih istraživanja. Laka dostupnost i niski troškovi omogućavaju brže i efikasnije sprovođenje istraživanja. Prema ESOMAR-ovom godišnjem izveštaju iz 2012. godine udeo onlajn istraživanja u odnosu na tradicionalna telefonska i terenska je u kontinuiranom porastu u svim zemljama sveta. Uprkos jasnim trendovima u svetu, u zemljama regiona i Srbiji udeo onlajn istraživanja je znatno manji u odnosu na druge tipove istraživanja koje agencije za istraživanje sprovode. U cilju ispitivanja trenutne situacije u oblasti onlajn istraživanja na domaćem tržištu, sproveden je niz strukturiranih intervjua sa predstavnicima domaćih agencija za istraživanje tržišta i marketinških agencija. Ispitanici su saglasni sa činjenicom da savremeno poslovanje nameće neophodnost razvoja istraživanja na Internetu, ali smatraju da, uprkos globalnom trendu rasta udela onlajn istraživanja u ukupnom korpusu istraživačkih usluga, naše tržište zaostaje kada je u pitanju ovaj specifični segment. Analizirani su potencijalni uzroci ovakve situacije i sagledane dalje perspektive razvoja industrije onlajn istraživanja u Srbiji.
\end{abstract}

\section{Ključne reči:}

tržišna istraživanja, online istraživanja, panel istraživanja.

\section{UVOD}

Uprkos relativno kratkom periodu upotrebe Interneta kao medija za implementaciju marketinških istraživanja, veliki broj autora smatra da su Internet bazirane metodologije i tehnike istraživanja u velikoj meri već postale rutina kako u akademskom radu tako i u praksi u najvećem broju istraživačkih i poslovnih oblasti (Farel \& Petersen, 2010; Behr et al., 2012; Bredl, Hunniger \& Jensen, 2012). Tehnološki razvoj u proteklom periodu promenio je paradigmu rada, komunikacije, kolaboracije pa i dnevnog funkcionisanja; u relativno kratkom vremenskom periodu život je postao nezamisliv bez upotrebe novih tehnologija, a korišćenje istih postalo je obavezan aspekt mnogih poslovnih oblasti. Internet je doneo niz novih mogućnosti u savremenom poslovanju omogućavanjem pristupa informacijama, deljenja znanja, povećavanja efikasnosti poslovnih procesa, pristupa većem broju korisnika - potencijalnih klijenata ili kupaca i donošenjem personalizacije i individualizacije poslovnog pristupa posebno u periodu intenzivnog razvoja društvenih mreža i medija.

Informacione tehnologije i Internet doneli su nove pristupe u marketingu i integrisanim komunikacijama, ostvarivši uticaj na skoro sve marketinške koncepte i alate. Marketinška istraživanja tradicionalno uključuju širok spektar potencijalnih ak-

\section{Abstract:}

Online market research has become an increasingly prevalent method of data collection in the area of market and social research. Lower costs and greater availability enable conducting research faster and more efficiently. According to ESOMAR's annual report from 2012., the global share of online research is continuously growing compared to traditional telephone and field research. Despite the global trends, the share of online market research in Serbia and the neighbouring countries is still lower compared to other types of market research conducted by research agencies. A series of structured interviews with the representatives of the local market research and marketing agencies was conducted in order to collect data on the current situation in this field. Research indicates that the participants fully agree that modern business demands research development on the Internet. However, they believe that the Serbian market is greatly lagging behind in terms of online research services. The potential reasons for this situation are discussed along with further development perspectives in online research industry in Serbia.

\section{Key words:}

market research, online research, panel research.

tivnosti: pregled sekundarnih izvora, kvalitativna istraživanja putem intervjua ili fokus grupa, posmatranje, eksperimenti ili upitnici, sve ove istraživačke metode u zavisnosti od predmeta istraživanja imaju značaj u prikupljanju informacija za donošenje marketinških odluka. Međutim, posle perioda ogromnog rasta i razvoja primene kvantitativnih istraživanja u periodu do 1990. godine, sredinom 90-tih godina otpočinje period pada stopa participacije ispitanika u anketama, slabljenje standardnog uzoračkog okvira kao i geometrijski rast podataka generisanih putem Interneta.

U eri digitalnih komunikacija sve ove istraživačke metode, kvalitativne i kvantitativne u velikoj meri se prenose u okruženje na Internetu otvarajući novo polje i metode istraživanja kao i čitav niz metodoloških pitanja vezanih za koncipiranje, planiranje i implementaciju kvalitativnih i kvantitativnih istraživanja na Internetu. Uprkos relativno kratkom periodu upotrebe Interneta kao medija za marketinška istraživanja veliki broj autora smatra da su Internet bazirane metodologije i tehnike istraživanja u velikoj meri već postale rutina kako u akademskom radu tako i u praksi u najvećem broju istraživačkih oblasti (Farel \& Petersen, 2010; Behr et al., 2012; Bredl, Hunniger \& Jensen, 2012; Denissen, Neumann \& van Zalk, 2010). Korišćenje Interneta u svrhe istraživanja javnog mnjenja i istraživanja tržišta, u proteklih deset godina u razvijenim zemljama, postala su industrija vredna milijarde dolara (Farel \& Petersen, 2010). 
Paralelno sa razvojem Internet tehnologija i sve većom penetracijom ove vrste istraživanja $u$ istraživačku praksu primećeno je da tradicionalne metode istraživanja, posebno kada su u pitanju kvantitativna istraživanja putem anketiranja ispitanika počinju da podbacuju u nekim segmentima. Na primer Bennet $i$ Nair (2010) navode da je dobijanje reprezentativnog uzorka putem korišćenja CATI (computer assisted telephone interviewing) tehnologija telefonskog intervjuisanja, koja je još uvek jedna od najpopularnijih metoda kvantitativnog marketinškog istraživanja, u poslednjih nekoliko godina znatno otežano, što zbog povećanog korišćenja tehnologija za proveru neželjenih telefonskih poziva, što zbog sve veće penetracije mobilnih telefona koji standardno nisu uključeni u ovakav vid istraživanja. Osim toga, pokazuje se da postoji tendencija ispitanika određenih sociodemografskih profila da u većoj ili manjoj meri odgovaraju na telefonski sprovođene ankete; primećeno je da žene odgovaraju češće od muškaraca, pripadnici mlađe generacije odgovaraju na telefonske ankete ređe od pripadnika starije generacije i sl. (Chang \& Krosnick, 2009).

Sve veći broj autora zastupa tezu da marketinško istraživanje sprovedeno na Internetu može biti urađeno na način da donese reprezentativne podatke za određenu ciljnu grupu. Uprkos činjenici da su u veb baziranim anketama određeni segmenti populacije reprezentovani u većem procentu nego u generalnoj populaciji (pre svega mlađa generacijska kohorta) korišćenje Interneta u generalnoj populaciji je u ovom trenutku preko $75 \%$ u Severnoj Americi (Farel \& Petersen, 2010) a ti procenti su daleko veći u određenim poduzorcima - u studentskoj populaciji se na primer kreću do 98\% (Ljepava et al., 2013). Ovakva penetracija Interneta stvara preduslove za kvalitetnije uzorkovanje, posebno kada je reč o mlađim generacionim kohortama.

Prema podacima agencije Inside Research $43 \%$ od ukupnog broja marketinških anketa je u 2010. godini u Sjedinjenim Američkim Državama sprovedeno onlajn. Tu nisu u pitanju samo standardna istraživanja Business to Consumer (B2C) već se sve veći broj poslovnih Business to Business (B2B) istraživanja takođe sprovodi ovim putem. Podaci istraživačke agencije Forrester Research ukazuju da od ukupnog broja onlajn istraživanja tržišta u Americi između 20 i 30\% odlazi na segment istraživanja u B2B sektoru.

Hesse-Biber i Griffin (2010) smatraju da istraživanja tržista putem Interneta još uvek ne bi trebalo posmatrati nezavisno, pre svega imajući u vidu potencijalne probleme koji mogu nastati kada je reč o reprezentativnosti onlajn uzorka, već da ih treba koristiti kao dopunu tradicionalnim istraživačkim metodama posebno u određenim tržišnim segmentima i ciljnim podgrupama.

Sprovođenje marketinških istraživanja na Internetu ima svoje prednosti i ograničenja kojih istraživači moraju biti svesni da bi na odgovarajući način bili u mogućnosti da postave metodološki okvir istraživanja. Neke od prednosti ovog načina istraživanja su omogućavanje anketiranja ispitanika koji su u udaljenim i manje pristupačnim oblastima, automatsko prikupljanje podataka koje smanjuje kako broj časova rada tako i mogućnost greške nastale prilikom unošenja podataka i sveukupno manju cenu implementacije ovakvih istraživanja u odnosu na standardne CATI ili CAPI (computer assisted personal interviewing) metode (Fan \& Yan, 2010)

Osim toga vođenje onlajn intervjua ili fokus grupa bilo putem sinhrone (istovremene) ili asinhrone (odložene) komunikacije na Internetu nudi značajne uštede i prednosti u odnosu na standardne metode sprovođenja ovakvog tipa istraživanja. Tako troškovi snimanja, opreme, putovanja ili telefona mogu biti eliminisani kao i troškovi transkripcije usmenih intervjua koji znaju da budu značajni.
Dodatna prednost i specifičnost ovog načina istraživanja, posebno kada je u pitanju kvalitativno marketinško istraživanje koje se sprovodi na Internetu (fokus grupe ili analiza diskursa koju je moguće sprovoditi u okviru diskusionih foruma i grupa a poslednjih godina i u okviru društvenih mreža i medijskih portala na kojima je omogućeno postavljanje korisničkih komentara) jeste što omogućava analizu specifičnih podgrupa sa sličnim interesima koji se u okviru tih foruma, grupa i društvenih mreža okupljaju a do kojih bi bilo teško ako ne i nemoguće doći kroz druge kanale. U mnogim slučajevima određene zajednice i grupe postoje samo u sajberprostoru, i provode značajan broj sati diskutujući o za njih relevantnim temama. Ovakve virtuelne zajednice mogu predstavljati kvalitetnu osnovu za kvalitativno istraživanje na Internetu budući da one nude mehanizme putem kojih istraživač može dobiti pristup specifičnoj usko targetiranoj ciljnoj grupi koja deli ista interesovanja i od koje se može dobiti kvalitetna povratna informacija o proizvodu ili usluzi koja se ispituje (Gruber et al., 2009).

Nedostaci ovakvog načina istraživanja u najvećoj meri se odnose na uzorkovanje i reprezentativnost Internet uzorka kao i na valjanost podataka prikupljenih na ovaj način budući da ne postoji mogućnost provere istinitosti unetih podataka, posebno kada su u pitanju demografski podaci ispitanika. Istraživanje sprovedeno na Internetu takođe ne dozvoljava kontrolu kvaliteta uzorka kakvu je moguće obaviti prilikom CATI istraživanja (pozivanje ispitanika slučajnim izborom radi provere da li su anketirani). Pored toga, istraživanja na Internetu koja nude podsticaje za učesnike, kakva imamo u brojnim agencijskim onlajn panelima, privlače određenu grupu ispitanika takozvanih profesionalnih učesnika u anketama, koji su motivisani eksternim nagradama i mogu dati nekvalitetne ili nedovoljno tačne podatke (Göritz, 2007).

Tehnologija sprovođenja istraživanja na Internetu unapređuje se iz dana u dan. Dok je donedavno kreiranje i postavljanje onlajn ankete predstavljalo komplikovan posao koji je podrazumevao poznavanje veb developmenta i HTML kodiranje, današnji programi za postavljanje anketa na Internetu imaju pregledne i jednostavne korisničke interfejse i za relativno kratko vreme omogućavaju postavljanje anketa. Mnogi od ovih programa ne samo da omogućavaju postavljanje anketa već imaju opcije analize podataka, koje su u slučaju nekih komercijalnih servisa poput kanadskog FluidSurvey ili američkog Survey Monkey sistema veoma napredne.

Osim toga, od preduslova za sprovođenje istraživanja na Internetu predstavlja i dovoljno veliki uzorak korisnika, kao i mogućnost njihove socio-demografske segmentacije u skladu sa potrebama istraživanja. $U$ tu svrhu sve veći broj agencija počeo je da se oslanja na veb panel softvere - baze podataka potencijalnih učesnika istraživanja putem kojih se šalju pozivi za popunjavanje anketa. Učesnici istraživanja se prijavljuju na panel sistem i dobijaju pozive za popunjavanje anketa u skladu sa socio-demografskim podacima koje su na panelu ostavili. Zauzvrat oni prikupljaju određen broj bodova po popunjenoj anketi koje mogu zameniti za vaučere za različite proizvode ili usluge.

Veb paneli postaju sve rasprostranjeniji vid prikupljanja podataka prilikom sprovođenja istraživanja na Internetu; neki od panela u razvijenim zemljama broje i više od 100.000 učesnika koje je moguće demografski segmentirati i istraživanje uraditi na tačno određenoj ciljnoj grupi. Neke kompanije poput Cint-a prepoznale su potencijal ovakvih istraživanja, i ponudile integraciju veb panela različitih agencija kroz koje se onda klijentima nudi baza učesnika iz većeg broja panela sa određenog područja, a agencije ostvaruju prihode shodno broju učesnika 
regrutovanih sa njihovih panela. Ovakav integrativni pristup je od posebnog značaja za manje zemlje u kojima veb paneli još uvek nisu razvijeni u većem stepenu, pošto omogućava pristup širem uzorku od onoga koji individualna agencija može da ponudi.

Navedene tehnološke pogodnosti su omogućile dalji razvoj kvantitativnog istraživanja na Internetu i veću penetraciju istih u okviru ukupnog broja marketinških istraživanja. Međutim, razvoj softverskih servisa za onlajn anketiranje i analizu podataka ima i negativnu stranu. Imajući u vidu jednostavnost korišćenja takvih alata mnoge kompanije se odlučuju da radi uštede ne angažuju profesionalne istraživače već da istraživanje obavljaju sami što može dovesti do lošeg metodološkog koncipiranja istraživanja i loše struktuiranih anketa koje rezultuju netačnim i slabo upotrebljivim podacima.

Kada je reč o trenutnoj situaciji u Srbiji po pitanju istraživanja koja se sprovode na Internetu, dostupno je malo ili nimalo podataka o tome. Iako većina agencija u svojoj ponudi danas ima istraživanja na Internetu, malo njih daje detaljnije podatke o tome na koji način se ta istraživanja vrše i kakav je uzorački okvir istraživačkih panela ukoliko ih ima.

U okviru ovog istraživanja po prvi put su ispitane poslovne prakse i trenutna ponuda na tržištu marketinških istraživanja na Internetu u Srbiji. Predstavnici agencija odgovarali su na dve grupe pitanja. Prva grupa pitanja odnosila se na stepen u kome u svom svakodnevnom poslovanju uzimaju u obzir trendove vezane za nove tehnologije i Internet, na koji način o tome komuniciraju sa klijentima i kakvi su zahtevi klijenata u ovoj oblasti. Takođe, u ovom segment učesnici su dali i svoje procene vezano za trenutnu i buduću situaciju na tržištu u Srbiji kada su u pitanju ovakva istraživanja kao i o tome kako generalno vide budućnost istraživanja na Internetu. Drugi set pitanja vezan je za konkretne prakse korišćenje Interneta i društvenih mreža $\mathrm{u}$ istraživačke svrhe, na koje načine agencije sprovode onlajn istraživanja i sa kojim problemima se pri tome suočavaju. Svi podaci su kumulativno analizirani i sortirani po kategorijama.

\section{REZULTATI I DISKUSIJA}

Istraživanje je obavljeno u periodu od decembra 2014. do marta 2015. godine. U istraživanju su učestvovali predstavnici 15 agencija iz Srbije koje se ili direktno bave istraživanjem tržišta kao glavnom delatnošću (agencije za marketinška istraživanja) ili za potrebe svog poslovanja naručuju ili samostalno sprovode istraživanja putem Interneta (agencije za marketing i komunikacije, agencije specijalizovane za digitalni marketing). Preko $80 \%$ ispitanih agencija koje su učestvovale u istraživanju nalazi se u Beogradu (81\%), dve agencije se nalaze u Novom Sadu (13\%), a jedna agencija u Nišu (6\%). Istraživanje je zamišljeno kao struktuirani intervju od 10 pitanja raspoređenih u dva segmenta - prvi vezan za percepciju trenutne situacije na tržištu, potencijale razvoja poslovanja u ovoj sferi kao i odnose sa klijentima, i drugi vezan za implementaciju istraživanja na Internetu, trenutne prakse rada kao i tipove istraživanja koje agencija obavlja.

Svi ispitanici smatraju da na rad njihove agencije razvoj informacionih tehnologija i Interneta utiče u znatnoj meri. Agencije koje se bave digitalnim marketingom su i direktno usmerene na aktivnosti koje obavljaju na Internetu i društvenim mrežama, ali i predstavnici ostalih agencija napominju da je uticaj koji Internet ostvaruje na moderno društvo i komunikacije veliki i da ga je potpuno nemoguće ignorisati u savremenom poslovanju.
Neki od navoda ispitanika:

"Pred klijentima se nalazi čitav dijapazon novih usluga, ne samo sa našeg tržišta nego i tržišta okolnih zemalja. Naprednije zemlje diktiraju trendove koji se prenose kod nas.“

„Sve sto utiče na potrošača je bitno našim klijentima i mi zato moramo razumeti sta je Internet promenio u ponašanju potrošača."

Kada je reč o informisanosti klijenata o mogućnostima koje pružaju društvene mreže i Internet pružaju, tri četvrtine ispitanika (75\%) smatra da prosečan klijent u Srbiji još uvek nije dovoljno informisan o potencijalima koje ovakav tip istraživanja može da im donese. Postoji bazična svest o stepenu penetracije Interneta u okviru određenih ciljnih grupa i mogućnostima koje to $\mathrm{u}$ istraživanjima tržišta i javnog mnjenja nosi. Međutim, većina ispitanika navodi da retko susreću klijente koji u toj oblasti tačno znaju šta žele da dobiju i na koji način. Više od polovine agencija (60\%) navodi da im je u ovom trenutku u fokusu edukacija tržišta o mogućnostima u ovoj oblasti, i da smatraju da se kroz edukaciju trenutno ojačava ovaj segment poslovanja i stvaraju uslovi za većom potražnjom za ovom vrstom usluga. Agencije koje posluju regionalno ili sa međunarodnim kompanijama imaju drugačija iskustva budući da predstavnici tih kompanija već tačno znaju šta je ono što traže i dolaze sa jasno definisanim zahtevima za određeni tip istraživanja i uzorka. Ta istraživanja su neretko deo obimnijih međunarodnih istraživanja, tako da se agencijski posao u tom slučaju svodi na prikupljanje podataka po unapred definisanoj metodologiji.

O informisanosti klijenata, ispitanici imaju sledeće mišljenje:

„Klijenti nisu u dovoljnoj meri edukovani o mogućnostima Interneta. Mahom imaju samo okvirnu sliku, a prodaja naših usluga često se svodi na edukaciju."

„Klijentima preporučujemo različite tipove istraživanja na Internetu u skladu sa njihovim potrebama, edukujemo ih i predstavljamo mogućnosti. Retko ko od domaćih klijenata dođe sa jasno definisanim predlogom istraživanja koje im je potrebno."

Iako preko $80 \%$ ispitanika smatra da će se tržište istraživanja na Internetu u narednom periodu širiti, većina (73\%) ne smatra da će ovaj tip istraživanja u skorije vreme postati primarni u Srbiji. Ovde je primetna razlika između ispitanika iz tradicionalnih kompanija za istraživanje tržišta i kompanija koje se u većoj meri bave digitalnim komunikacijama. Dok predstavnici prve grupe smatraju da Internet nikada u potpunosti neće zameniti istraživanja koja se obavljaju na generalnoj populaciji, predstavnici digitalnih agencija smatraju da je implementacija istraživanja na Internetu sa nacionalno reprezentativnim uzorcima samo pitanje vremena.

Kao generalni problem koji trenutno zapažaju u poslovanju u Srbiji, ističe se smanjenje potražnje na tržištu kada su u pitanju usluge istraživanja usled ekonomske krize, kao i pad cena usluga, što dovodi do otežanog razvoja i plasmana inovativnih servisa i dodatnih usluga. Sa druge strane, ovu situaciju ipak vide kao privremenu i smatraju da je perspektiva razvoja ovih istraživanja velika, posebno imajući u vidu njihovo efikasno i brzo sprovođenje i niske cene:

„U situaciji stešnjenih ekonomskih mogućnosti tržišta, istraživanja se često tretiraju kao luksuz, a ne kao potreba. Ipak, zbog svoje ekonomičnosti, istraživanja na Internetu u ovim uslovima mogu samo rasti. Svaka kriza prođe pre ili kasnije, a istraživanja na Internetu će se razvijati. Stoga mislim da ova grana istraživanja definitivno ima perspektivu." 
Kao probleme u ovoj sferi istraživanja ispitanici vide laku dostupnost Internet istraživanja i alata za istraživanje i kreiranje loših istraživačkih instrumenata od strane nedovoljno stručnih individua. Osim toga, jedan od problema koje donosi Internet je i generisanje velikog broja podataka, što se posebno odnosi na analizu kvalitativnih podataka, i analize sadržaja i diskursa. Velike baze podataka zahtevaju sofisticirane metodološke pristupe kao i specijalizovane softvere, a problem naših agencija je kako manjak usko stručnog kadra za analizu velikih setova podataka, tako i cene softvera za ovu analitiku koje mogu iznositi i više desetina hiljada dolara za posebno specijalizovane programe.

Kada je reč o izazovima koje se pred agencije postavljaju prilikom sprovođenja ovog tipa istraživanja, neki od ispitanika navode:

„Istraživanje na Internetu danas može obaviti praktično bilo ko koristeći besplatne verzije Internet softvera za kreiranje na prvi pogled loših istraživačkih istrumenata, ta istraživanja se sprovode na uzorku koji ne respondira ni sa jednom populacijom osim sa populacijom onih koji su uradili tu anketu, itd."

„Što je vise ljudi na Internetu to će ovo mesto za istraživanje postati važnije. Tradicionalne istraživačke agencije je sve lakše obići kada je prikupljanje podataka u pitanju, jer kompanije i same mogu da organizuju svoja istraživanja (za odredjene teme), ali se postavlja pitanje metodologije kao i to kako sve brojnije podatke tumačiti i povezati."

Sve anketirane agencije u određenoj meri sprovode istraživanja na Internetu. Internet se koristi za sprovođenje različitih tipova istraživanja, od pilot istraživanja i istraživanja zadovoljstva zaposlenih do istraživanja javnog mnjenja, kao i širih marketinških istraživanja koje sprovode isključivo one agencije koje imaju sopstvene veb panele. Pored toga oko polovina ispitanika se izjasnila da se istraživanja koriste i za istraživanja ponašanja i preferencija korisnika društvenih mreža. Ovde prednjače agencije koje su specijalizovane za digitalni marketing, ali se i standardne marketinške agencije odlučuju da ovakav tip istraživanja interno rade po potrebama, posebno u situacijama kada je potrebno formirati određenu marketinšku ili komunikacionu strategiju ili testirati određeni koncept ili dizajn na vebu.

Kada su u pitanju kvalitativna istraživanja, gotovo polovina ispitanih agencija poseduje specijalizovane softverske alate za sprovođenje ovakvih istraživanja (53\%). Po pravilu, u pitanju su agencije za istraživanje tržišta koje su deo neke veće međunarodne mreže, gde se vršio direktan prenos praksi i iskustava sa drugih tržišta koje su već primenjivale ovaj tip istraživanja. Kvalitativna istraživanja vrše se putem specijalizovanih platformi na kojima ispitanici diskutuju, ostavljaju mišljenje o proizvodima, uslugama, kampanjama i slično, pa se njihovi odgovori zbirno analiziraju i kategorizuju kao u slučajevima standardnih fokus grupa. Sa druge strane, neke od agencija koje poseduju ovakve softverske alate napominju da uprkos činjenici da raspolažu ovakvom tehnologijom, interesovanje za ovaj tip istraživanja nije veliko.

Kada su u pitanju veb paneli oko $80 \%$ anketiranih agencija za istraživanje tržišta ili trenutno poseduje veb panel ili ga razvija. Izuzetak su male agencije koje ne postoje dugo na tržištu i koje nisu imale mogućnosti da ulažu u razvoj panela. Ipak, predstavnici tih agencija smatraju da je ovaj tip istraživanja značajan i da ga je potrebno razvijati u budućnosti. Kada je reč o brojnosti panela neke od agencija nisu bile voljne da daju podatke o broju trenutnih učesnika u panelu. Kod preostalih agencija broj učesnika se kreće od 2.000 do 10.000 panelista. Jedan od panela nalazi se u Cint mreži preko koje se usluge panel istraživanja u Srbiji nude različitim agencijama u regionu i globalno.

\section{REZIME}

Rezultati istraživanja jasno ukazuju na to da je u agencijama koje se u Srbiji bave marketingom i marketinškim istraživanjima izgrađena svest o značaju i mogućnostima istraživanja koja se sprovode na Internetu. U zavisnosti od mogućnosti, resursa i okolnosti poslovanja, većina agencija implementira neku vrstu Internet istraživanja. Kod marketinških i digitalnih agencija većinom su u pitanju istraživanja koja se rade interno i koja su bitna za dalje formulisanje komunikacionih i marketinških strategija, dok se kod agencija koje se bave istraživanjem tržišta i javnog mnjenja ove usluge uglavnom nalaze u standardnoj ponudi istraživačkih usluga.

Uprkos tome što u agencijama postoji svest o mogućnostima koje pruža Internet u poslovanju i specifično istraživanja na Internetu, u Srbiji još ne postoji dovoljno izgrađeno i zrelo tržište za ovaj tip usluga. Kompanije koje imaju jasno definisane zahteve u ovom segmentu uglavnom su ili međunarodne kompanije ili kompanije koje se specijalizovano bave tehnologijama i Internetom, pa su dovoljno upućene u mogućnosti ovakvih vrsta istraživanja. Ispitanici posebno naglašavaju činjenicu da je srpsko tržište kada je u pitanju istraživanje na Internetu još uvek u fazi razvoja, i da je pre nego što bude moguć veći razvoj ovog segmenta poslovanja potrebna šira edukacija tržišta o mogućnostima ovakvog vida istraživanja.

Agencije najčešće sprovode kvantitativna istraživanja putem upitnika dok su kvalitativna istraživanja zastupljena u manjoj meri. Većina agencija koja se bavi istraživanjem tržišta, kao glavnom delatnošću, poseduje ili razvija onlajn istraživački panel. Sa druge strane, broj učesnika tih panela, u ovom trenutku, nije dovaljan za sprovođenje istraživanja koje bi omogućilo kvalitetnu socio-demografsku segmentaciju ispitanika. Prema podacima ESOMAR-a broj participanata onlajn panela mora biti preko 10.000 da bi se obezbedio minimum kvaliteta $\mathrm{u}$ istraživanju putem Interneta, a ti brojevi u internacionalnim panelima idu i do više desetina hiljada. Pored regrutacije ispitanika za onlajn panele, kao jedan od potencijalnih problema sa kojima se suočavaju, predstavnici agencija za istraživanje tržišta navode i to da se onlajn istraživanja zbog svoje dostupnosti često rade interno i bez definisanih metodologija i konsultacija sa profesionalnim istraživačima što može voditi do loše koncepcije istraživanja i iskrivljivanja rezultata istraživanja.

Svetski trendovi u istraživanjima na Internetu su jasni, a porast u udelu ovih istraživanja u razvijenim zemljama raste na godišnjem nivou. Iako među profesionalcima u ovom polju u Srbiji postoji svest o mogućnostima istraživanja na Interntetu, za rast ovog segmenta poslovanja potrebna je na prvom mestu edukacija tržišta, a onda i stvaranje adekvatnog podsticajnog poslovnog okruženja u kome će agencije biti u mogućnosti da uspešno posluju i ulažu u razvoj i unapređenje usluga koje nude.

\section{LITERATURA}

Behr, D., Kaczmirek, L., Bandilla, W., \& Braun, M. (2012). Asking probing questions in web surveys: Which factors have an impact on the quality of responses? Social Science Computer Review, 30, 487-498.

Bennett, L., \& Nair, C.S. (2010). A recipe for effective participation rates for web based surveys. Assessment \& Evaluation in Higher Education, 35, 357- 365.

Bredl, K., Hunniger, J., \& Jensen, J.L. (2012). Methods for analyzing social media: Introduction to the special issue. Journal of Technology in Human Services, 30, 141-144. 
Chang, L., \& Krosnick, J.A. (2009). National surveys via rdd telephone interviewing versus the Internet comparing sample representativeness and response quality. Public Opinion Quarterly, 73, 641-678.

Denissen, J.J.A., Neumann, L., \& van Zalk, M. (2010). How the Internet is changing the implementation of traditional research methods, people's daily lives, and the way in which developmental scientists conduct research. International Journal of Behavioral Development, 34, 564-575.

Fan, W., \& Yan, Z. (2010). Factors affecting response rates of the web survey: A systematic review. Computers in Human Behavior, 26, 132-139.

Farrell, D., \& Petersen, J.C. (2010). The growth of Internet research methods and the reluctant sociologist. Sociological Inquiry, 80, 114-125.
Göritz, A.S. (2007). Using online panels in psychological research. In A. Joinson, K. McKenna, T. Postmes \& U. Reips (Eds.), The Oxford handbook of Internet psychology (pp. 473486). Oxford, UK: Oxford University Press.

Gruber, T., Szmigin, I., Reppel, A.E., \& Voss, R. (2008). Designing and conducting online interviews to investigate interesting consumer phenomena. Qualitative Market Research: An International Journal, 11, 256-274.

Hesse-Biber, S., \& Griffin, A.J. (2013). Internet-mediated technologies and mixed methods research: Problems and prospects. Journal of Mixed Methods Research, 7, 43-61.

Ljepava, N., Orr, R.R, Locke, S., Ross, C (2013). Personality and social characteristics of Facebook non-users and frequent users. Computers in Human Behaviour, 29(4), 1602-1607. 